\title{
ACENTO E RITMO: ASPECTOS FONÉTICO-PROSÓDICOS NO ENSINO DE INGLÊS COMO L2
}

Leônidas José da Silva Junior*

\begin{abstract}
Resumo: O presente trabalho tem como objetivo contribuir para a aquisição do inglês como L2 a partir de aspectos prosódicos. Nossa pesquisa se aporta nos estudos de Ladefoged; Disner (2013), Avery; Ehrlich (2012), Alves (2012), Roach (2009, 2005), Jenkins (2000), Pike (1945) dentre outros. Na metodologia, fizemos coleta de dados orais com um norte americano e três brasileiros com proficiência advanced. Após a coleta, analisamos os dados acusticamente para verificarmos a influência que o acento e ritmo da L1 exercem nas produções de L2. Nossos resultados apontaram que ocorre transferência fonológica do ritmo L1 $\rightarrow \mathrm{L} 2$. Concluímos que o professor de língua inglesa deve privilegiar aspectos fonético-prosódicos da L2 para que o processo de aquisição e/ou aprendizagem seja mais efetivo.
\end{abstract}

Palavras-chave: Acento. Ritmo. Inglês como L2.

\begin{abstract}
This paper aims to contribute to EFL acquisition from prosodic aspects of the language. Our research framework is based on Disner; Ladefoged (2013), Avery; Ehrlich (2012), Alves (2012) Roach (2009, 2005), Jenkins (2000), Pike (1945) and others. Methods consisted in collecting audio data from an American and three Brazilian speakers English-advanced-leveled. After data collection, we made acoustic analysis to verify the influence of the stress and rhythm of L1 on L2 productions. Our results show occurrence of phonological transfer of L1 on L2. We conclude that English teachers should focus on phonetic-prosodic aspects of L2 so that the process of acquisition and/or learning will be more effective.
\end{abstract}

Keywords: Stress. Rhythm. EFL.

\section{Introdução}

A aquisição da língua inglesa como língua estrangeira (doravante, L2) no Brasil vem, a partir da segunda guerra mundial e mais acentuadamente após o fim da década de 1980, tornando-se mais importante na vida cotidiana e principalmente no mundo do trabalho. Silveira (2011) afirma que este fato desemboca em uma maior valorização deste componente no PCNEM ${ }^{1}$ e, dessa forma, reconhece que o aprendizado de suas habilidades é relevante.

Segundo Jenkins (2000), as últimas décadas têm testemunhado a ascensão da língua inglesa, partindo de status de uma língua internacional, para um status de ser a primeira língua verdadeiramente global; sendo um meio através do qual as pessoas de todas as partes do mundo podem se comunicar uns com os outros, especialmente nos campos da ciência e tecnologia, comércio, educação, mídia, segurança internacional e viagens internacionais. Por esta razão, estudos em torno de como o ensino de língua inglesa têm sido realizado merecem especial atenção, visto que os professores formam cidadãos para atuarem de modo interacional e inteligível com outros falantes de inglês do mundo.

No que tange a questões fonético-fonológicas, a maioria dos professores que detém domínio de pronúncia em língua inglesa prioriza o ensino de pronúncia dando ênfase apenas aos traços segmentais, ou seja, ao quadro fonêmico do inglês e que estes são menos relevantes à comunicação do que o domínio de traços suprassegmentais, uma vez que os aspectos fonológicos não-lineares carregam um valor significativamente maior para inteligibilidade na troca conversacional como afirmam Roach, (1982), Celce-Murcia (2010) e Avery; Ehrlich (2012).

\footnotetext{
* Professor Adjunto do Departamento de Letras/CH na Universidade Estadual da Paraíba (UEPB/CAPES). Endereço eletrônico: leonidas.silvajr@gmail.com

${ }^{1}$ PCNEM: Parâmetro Curricular Nacional do Ensino Médio.
} 
Em meio a esse e a tantos outros desafios, a compreensão e a produção oral da língua aparece como um dos principais obstáculos encontrados por falantes do inglês como L2 devido às diferenças encontradas entre o sistema fonológico da L2 e os do português brasileiro (doravante, PB) como língua materna (doravante, L1). Dessa forma, o que é de fato aprender outra língua, vai tornando-se cada vez menos responsabilidade das escolas de ensino regular, passando a ser compromisso das escolas de idiomas.

É interessante destacar que na maioria dos casos os estudantes não têm consciência de que os sons entre uma língua e outra se diferenciam. Mascherpe (1970) já apontava que no início da aquisição - o estudante ouvirá apenas os fonemas semelhantes aos de sua L1 e de maneira natural ele os transfere para L2 no momento da produção oral. Este processo é denominado transferência fonológica ${ }^{2}$ (doravante, TF) e se dá, dentre outros fatores, devido ao pouco acesso às habilidades orais (listening e speaking skills) que os estudantes têm da L2.

\section{Aporte teórico}

Segundo Celce-Murcia (2010), a fala no inglês não é produzida a partir de palavras isoladas, ao invés disso, elas tendem a "correr juntas". Este fenômeno é conhecido como 'fala encadeada' (connected speech) ou Variação de Sândi ${ }^{3}$ (sandhi variation). Devido a este fenômeno, podemos encontrar processos de reestruturação silábica (ressilabificação) e mudanças fônicas das vogais (alternância dos traços [ \pm forte/fraco] que se relacionam ao acento no domínio da palavra fonológica até o enunciado fonológico).

Ainda diz a autora que, mesmo nas aulas mais simples de inglês, nunca devemos ignorar as mudanças de pronúncia que ocorrem dentro e entre palavras, ou seja, aspectos de pronúncia que invocam justaposição de sons em ambientes fonológicos vizinhos. A juntura desses sons produzirá um efeito diferente no enunciado. Uma vez adjungidos, não só teremos segmentos isolados, mas sim, sílabas, palavras, frases e enunciados. Neste cenário, encontramos os aspectos rítmicos da língua.

\subsection{O ritmo linguístico}

O conceito de ritmo em Linguística é de que um dado movimento é marcado por sucessões regulares de tempo (isocronia) de batidas fortes e fracas em um ato de fala. O ritmo denota, portanto, seu envolvimento com eventos que acontecem em intervalos de tempo regulares (ROACH, 2005).

O ritmo da fala é um dos traços mais distintivos de uma língua. É adquirido na infância, tornando-se difícil passar por mudanças na fase adulta, isto é, fica mais difícil adquirir valores perceptuais como o ritmo, como é o caso, por exemplo, da aquisição do

\footnotetext{
${ }^{2}$ Transferência Fonológica (TF) é a tentativa de reprodução de fonemas desconhecidos ao arcabouço fonêmico do falante, ou seja, emprego de um fonema da L1 com alguma semelhança de ponto e/ou modo de articulação (STAMPE, 1973). Ao modelo de Stampe (1973), Silva Jr e Scarpa, (2015) acrescentam aos processos de TF padrões rítmicos da L1 para L2

${ }^{3}$ Variação de Sândi ou como denominado no inglês, sandhi variation, é um termo que deriva de Sânscrito e que se refere à juntura (placing together) de sons entre palavras. A variação de sândi ou simplesmente, Sândi, não se restringe unicamente ao inglês e é uma característica fonético-fonológica de todas as línguas naturais (cf. CELCE-MURCIA, 2010).

Clarey e Dixson (1963) chamam essa tendência de Lei da Economia (law of economy) em que os órgãos da fala, ao invés de se re-articularem em novas posições assumindo um novo ponto de articulação para cada segmento, tendem a "juntar" os traços, via regras autossegmentais, na intenção de economizar tempo e energia.
} 
inglês como L2 depois da adolescência. É possível que os adultos sejam "fonologicamente surdos" porque sua escuta já está assentada nos traços de sua língua materna (cf. DUPOUX; PEPERKAMP, 1999).

De acordo com Pike (1945), há uma dicotomização do ritmo em silábico e acentual. Pike (1945) propõe dois tipos rítmicos para classificar as línguas do mundo: stress-timed rhythm ou ritmo acentual - representando uma sucessão de alternância/batidas entre sílabas acentuadas e não-acentuadas, ou seja, isocronismo acentual; por exemplo, o inglês, russo e árabe; e syllable-timed rhythm ou ritmo silábico - representando uma sucessão de sílabas igualmente espaçadas e proferidas no tempo.

Recorre-se, pois, à Fonologia Prosódica ou simplesmente, Prosódia da Fala. Esta se constitui a partir do domínio da sílaba $(\sigma)$ subindo na árvore prosódica até o enunciado fonológico (U) como afirma Selkirk (1984). Vejamos, por exemplo, (1) e (2) Us com alternância de acento [ \pm forte/fraco]:

(1) this is a book - [ðə’sızə‘bok]

(2) this is an apple - [ðə’sızən'æpł]

\subsection{O ritmo e a aquisição de inglês como $\mathrm{L} 2$}

Durante o processo de aquisição de uma L2, os aprendizes se deparam com dificuldades de diferentes ordens - fonológica e morfossintática sendo, especialmente fonético-fonológicas. A interferência que a língua materna exerce sobre a língua estrangeira é, sem dúvida, um fator que condiciona fortemente essas dificuldades.

Os falantes nativos do PB, durante o processo de aprendizagem do inglês, transferem fenômenos lexicais, fonológicos e sintáticos, por exemplo, de sua L1 para a L2. Essa língua alvo, ainda em estado de desenvolvimento, que apresenta fortes influências da língua materna, recebe a denominação de Interlíngua (interlanguage) (SMITH, 1994).

O ensino de inglês, no que tange à inteligibilidade, tem sido negligenciado, uma vez que um significativo número de docentes de língua inglesa não incentiva os aprendizes às praticas envolvendo pronúncia em sala de aula.

Duas questões de grande relevância se dão em relação ao background do professor:

i) Será que este adquiriu em sua formação habilidades relacionadas à oralidade?

ii) Mesmo que o professor tenha aprendido a pronúncia adequada dos segmentos fonéticos a partir do inventário fonêmico do inglês, ele / ela adquiriu questões que tocam a constituição fonológica da língua inglesa nos níveis suprassegmentais como o ritmo?

Respondendo a primeira questão, muitas vezes, o professor traz pronúncia deficitária por não ter sido contemplada a oralidade em sua formação. Assim sendo, este profissional, na maioria das vezes, não dá a devida importância que a pronúncia exerce enquanto habilidade constitutiva ao bojo do falante.

Como resposta à segunda questão, Roach (1982), Celce-Murcia (2010) e Avery; Ehrlich (2012) afirmam que muitos professores que priorizam o ensino de pronúncia o fazem dando ênfase aos traços segmentais se limitando ao quadro fonêmico do inglês deixando de lado traços suprassegmentais.

Roach (1982) ainda afirma que o simples fato de dominar conteúdos gramaticais, deter grande quantidade de vocabulário, compreender estruturas morfossintáticas complexas e 
conhecer, em isolamento, os sons das vogais e consoantes tem sua importância, todavia, se o falante quer ser bem sucedido na produção de seus atos comunicacionais, ele/a deve priorizar a aquisição dos aspectos rítmicos da L2.

Roach (op. cit.) coloca que é na produção de sintagmas fonológicos que é mais perceptível e suscetível à TF o que demonstra que os processos e métodos usados para a aquisição de inglês como L2, em torno apenas de uma pronúncia que prioriza a fonologia serial - ou até mesmo - unicamente o ensino de regras gramaticais, deve ser revisitado.

\section{Metodologia}

A metodologia deste trabalho foi realizada com base na coleta de material fonético a partir de dados gravados por um total de quatro informantes, sendo um norte-americano (dos EUA) - grupo controle (GC) e três brasileiros - grupo experimental (GE).

A coleta foi feita de modo controlado para sustentar o cunho fonético do trabalho.

Os informantes leram um pequeno texto em que continha a seguinte frase-alvo: " $\boldsymbol{A}$ new algorhythm". A realização desta frase-alvo serviu para atestar nossa hipótese; de que a produção rítmica do brasileiro ao falar inglês como L2 se distancia da produção do norteamericano.

O informante 1, norte-americano - grupo controle (GC) - é falante de inglês como L1 e do PB como L2.

Dos brasileiros que compõem nosso corpus, todos são alunos do curso de LetrasInglês. O informante 2 é falante do dialeto de Recife/PE (estudante na UFPE), o informante 3 , falante do dialeto de João Pessoa/PB (estudante na UEPB) e o informante 4, falante do dialeto de Guarabira/PB (estudante na UEPB). Os três informantes são falantes proficientes de inglês como L2 (advanced - B1) de acordo com Oxford Online Placement Test (OOPT) ${ }^{4}$. Consideramos o nível de proficiência como única variável independente da presente pesquisa.

Os dados foram gravados na Biblioteca do Centro de Tecnologia e Geociência CTG/UFPE com o falante de Recife e o norte-americano e no Laboratório de Fonética LABFONE/UEPB -Campus III/CH com o informante de João Pessoa e o de Guarabira.

$\mathrm{Na}$ coleta de dados, utilizamos o gravador PCM Recorder Zoom H1 para obtenção de modelos e parâmetros acústicos mais precisos.

As análises foram realizadas sob o ponto de vista fonético-acústico através do Programa Computacional PRAAT versão 5.4 (Boersma; Weenik, 2014); disponível em: http://www.fon.hum.uva.nl/praat/. No programa, medimos o P-center e os intervalos interacentuais ${ }^{5}$ das sílabas que compõem as palavras da frase fonológica que utilizamos. Esta técnica foi utilizada por Marcus (1981) apud Couper-kuhlen (1993) e Barbosa (2000).

\footnotetext{
${ }^{4}$ O Oxford Online Placement Test (OOPT) auxilia no nivelamento do aprendiz para que este seja devidamente alocado em um ambiente condizente com a realidade de sua habilidades na língua inglesa (PURPURA, 2013). Disponível em: https://www.oxfordenglishtesting.com/.

${ }^{5}$ Segundo Barbosa (2000), O P-center (perceptual center) - (P) - seria a ponto no sinal acústico em que o ouvinte se ancoraria para perceber a sequência sonora (de sinal de fala) como ocorrendo a intervalos regulares o isocronismo acentual ou silábico. Segundo o autor, o $P$-center funciona como ponto de ancoragem universal para percepção de isocronismo.

Ainda sobre o P-center, Marcus (1981) apud Couper-Kuhlen (1993) e Barbosa (2000) definem que a determinação do local do P-center é cada momento de transição CV (consoante-vogal) estável na(s) palavra(s) que compõem a frase fonológica.

Segundo os autores, entre cada $P$-center figuram os intervalos interacentuais (interstress intervals) ou grupos interacentual (GIPC). Esses intervalos têm duração do onset da vogal ao onset da próxima vogal à sua direita; $\left(\right.$ GIPC $={ }_{\text {onset }} \mathbf{V}-$ onset $\left.V\right)$.
} 


\section{Resultados e discussão}

Vejamos a seguir, através de análise acústica, três imagens que mostram a produção da frase fonológica $(\varphi)^{6}[$ a new algorhythm $]$ :

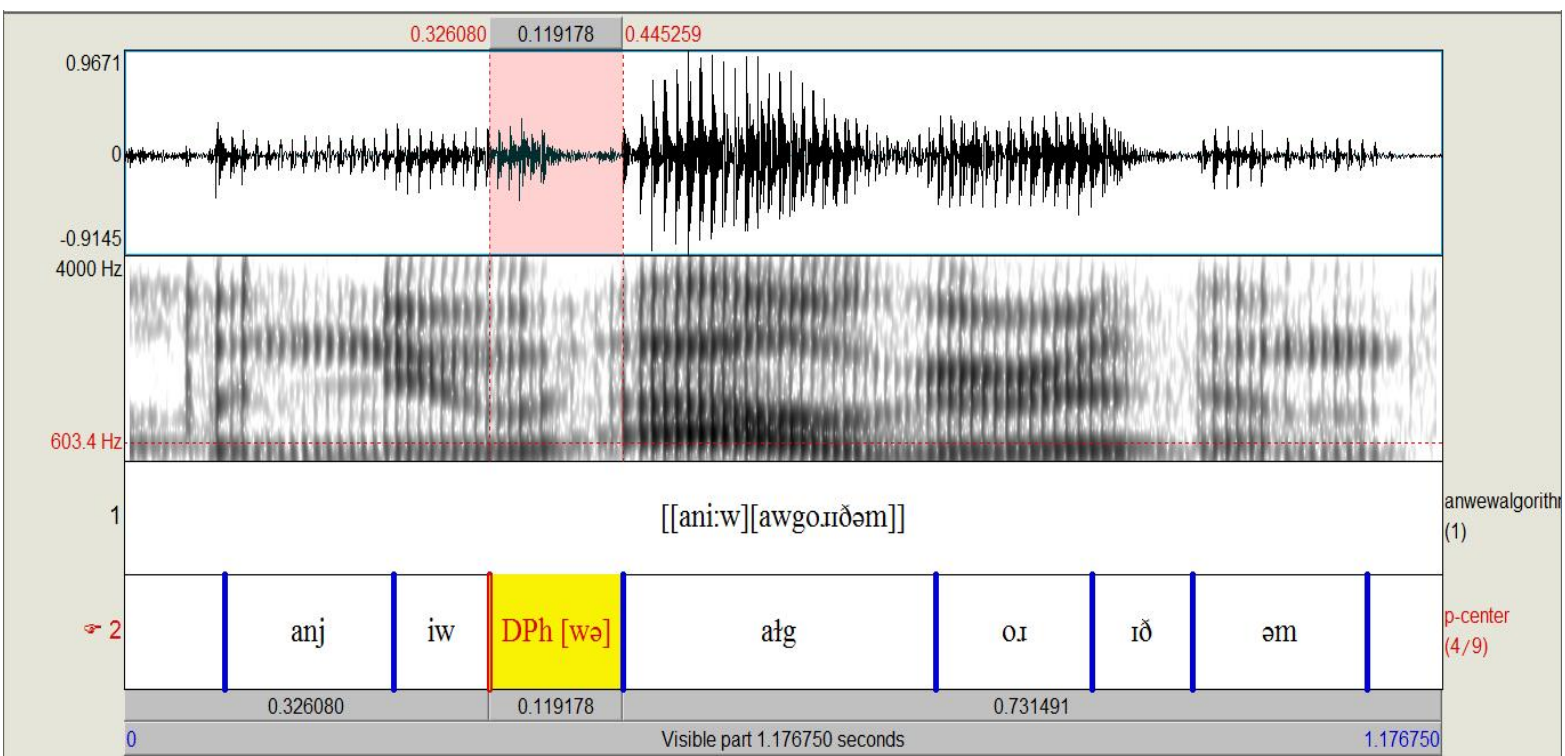

Figura 1: Sinal periódico, espectrograma com visualização de duração e transcrição fonética de [ $a$ new algorhythm $] \varphi$ produzida pelo falante estadunidense - informante 1.

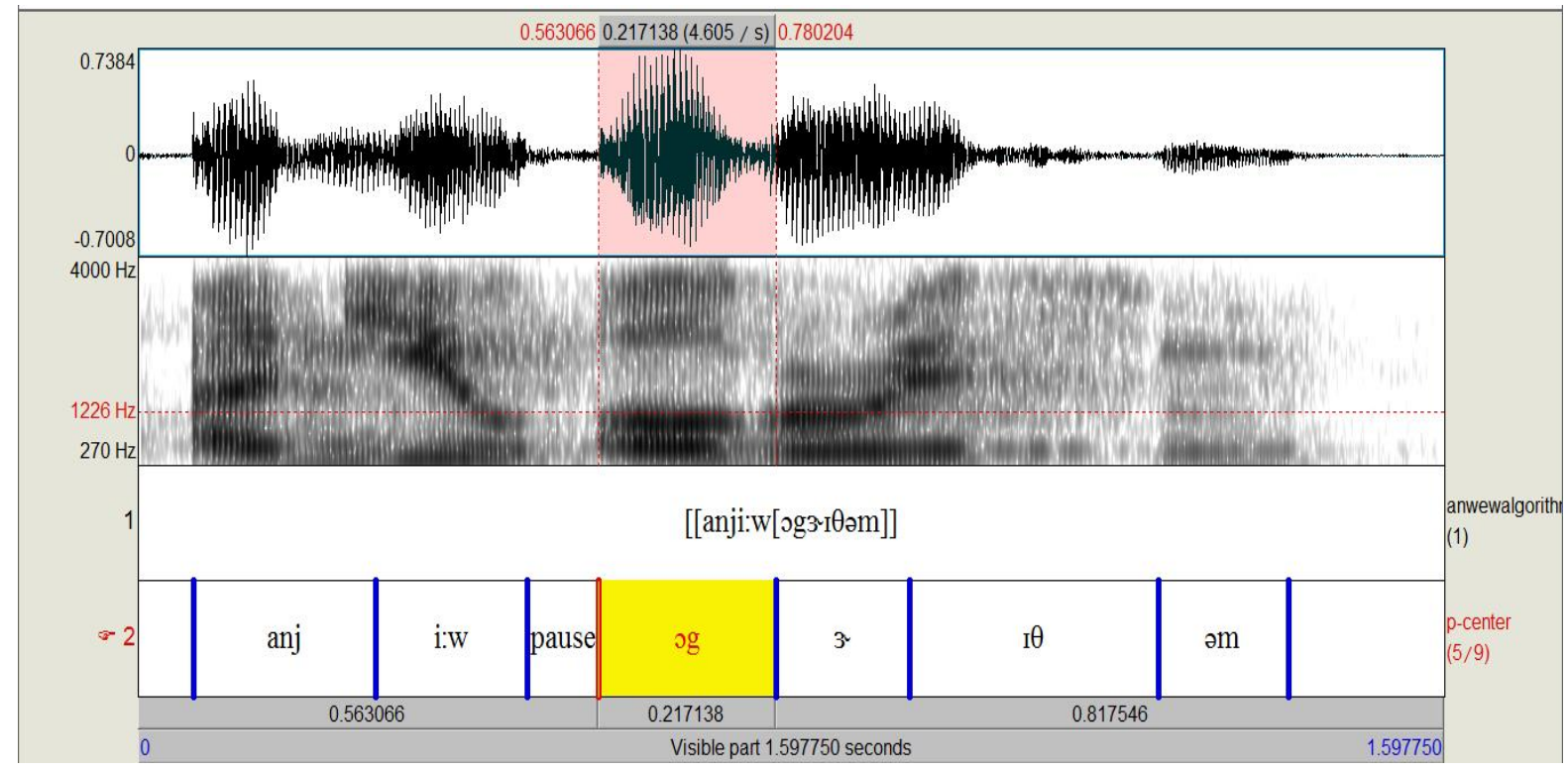

Figura 2: Sinal periódico, espectrograma com visualização de duração e transcrição fonética de [a new algorhythm] $\varphi$ produzida pelo falante brasileiro recifense - informante 2 .

${ }^{6}$ De acordo com Bisol (2010), a Frase Fonológica ( $\varphi$ ) é o quarto nível da arvore prosódica. É neste domínio que se verificam questões relacionadas ao ritmo. 


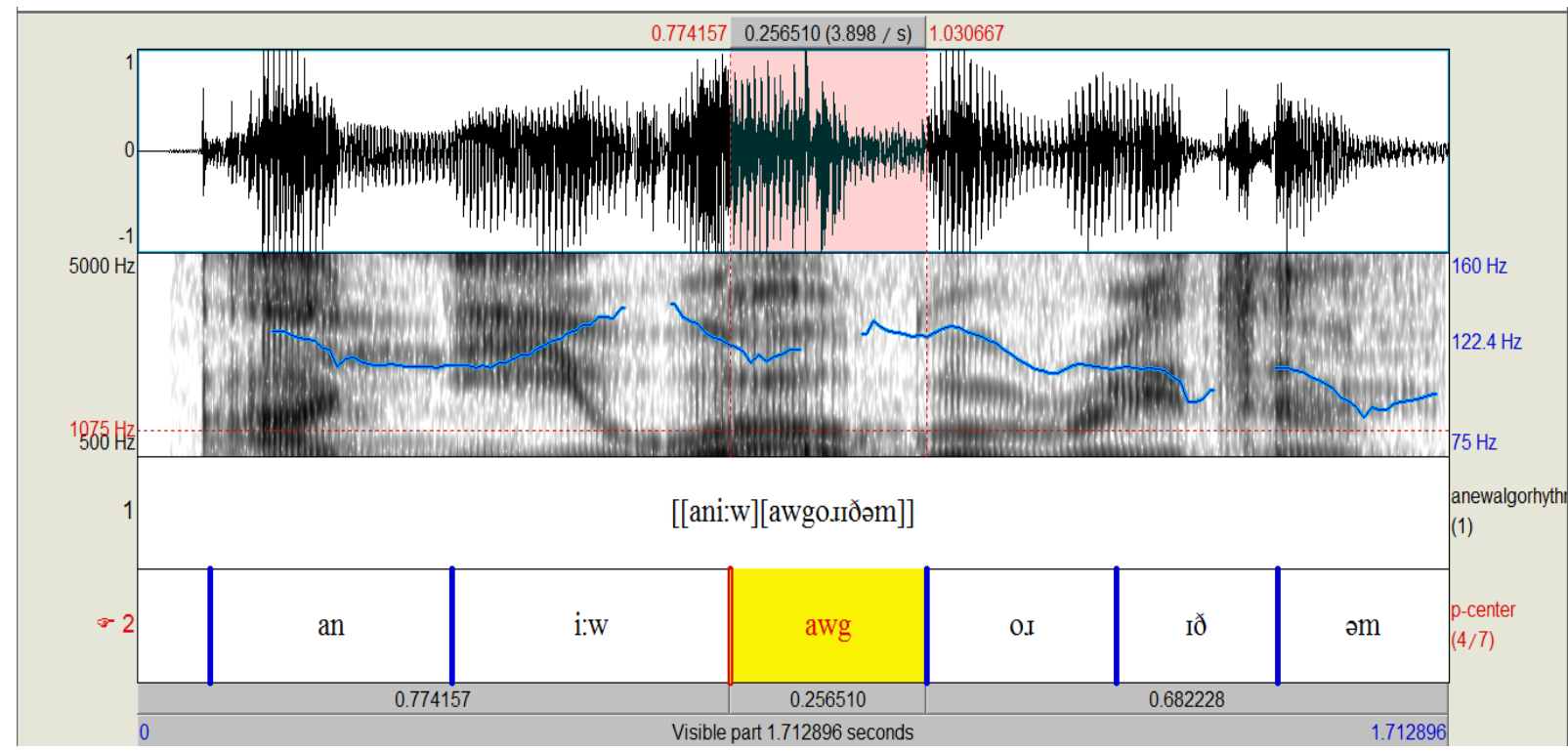

Figura 3: Sinal periódico, espectrograma com visualização de duração, $\mathrm{F}_{0}$ e transcrição fonética de [a new algorhythm] $\varphi$ produzida pelo falante pessoense - informante 3 .

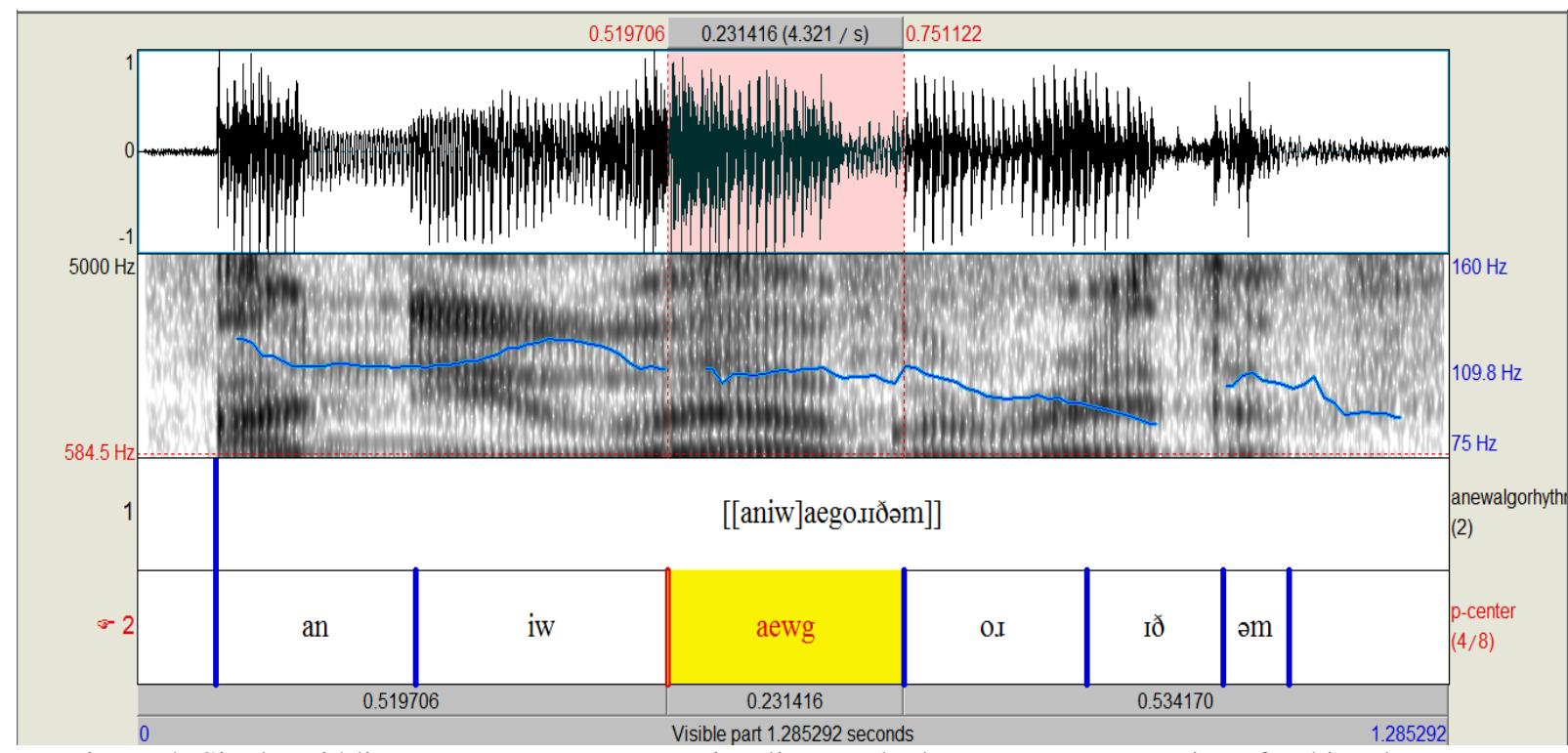

Figura 4: Sinal periódico, espectrograma com visualização de duração, $\mathrm{F}_{0}$ e transcrição fonética de [a new algorhythm $] \varphi$ produzida pelo falante guarabirense - informante 4.

Como mostram as Fig. 1, 2, 3 e 4 o inglês traz um ritmo diferente do PB. Logo, é seguro argumentar - com base em nossos dados - que o ritmo, neste caso, varia de uma língua para a outra. A produção da mesma frase é ritmicamente divergente quando comparamos a produção do falante norte-americano com a produção dos brasileiros. algorhythm".

Tal fato é atestado pela diferença entre a duração dos P-centers $(\mathrm{P})$ na $\varphi$ "a new

Testa-se na Fig. 1 que P[pł] (alg) - da palavra "algorhythm" ganha maior proeminência por ser mais longa que as demais. Esse processo fonológico é típico do inglês; tornar o acento frasal significativamente mais alongado que as demais sílabas/P-centers como afirmam Selkirk (1984), Hayes (1995) e Nespor; Vogel (2007). 
Ainda na Fig. 1, percebe-se no espectrograma uma janela denominada " $\mathrm{DPh} "$ (decelaration phase), em que ocorre uma fase de desaceleração dos articuladores que vai dos lábios durante a produção da aproximante [w], passando pela espaço medial da cavidade oral onde ocorre a produção de schwa [ə] na trajetória seguindo até a região sub-glótica em que as produções são reduzidas como apontam os estudos de Fichs, Perrier e Mooshammer (2001). Para calcular a DPh utilizamos uma função periódica representada por (3):

$$
\text { (3) } f(x+T)=f(x)
$$

A função representada em (3) traz valores em que $x=F 2$ do intervalo e $T$ é a representação do período na trajetória de F2. Esta fase de desaceleração pode ser constatada no Gráfico 1 no qual utilizamos as medidas de dez amostras de F2 do referido intervalo:

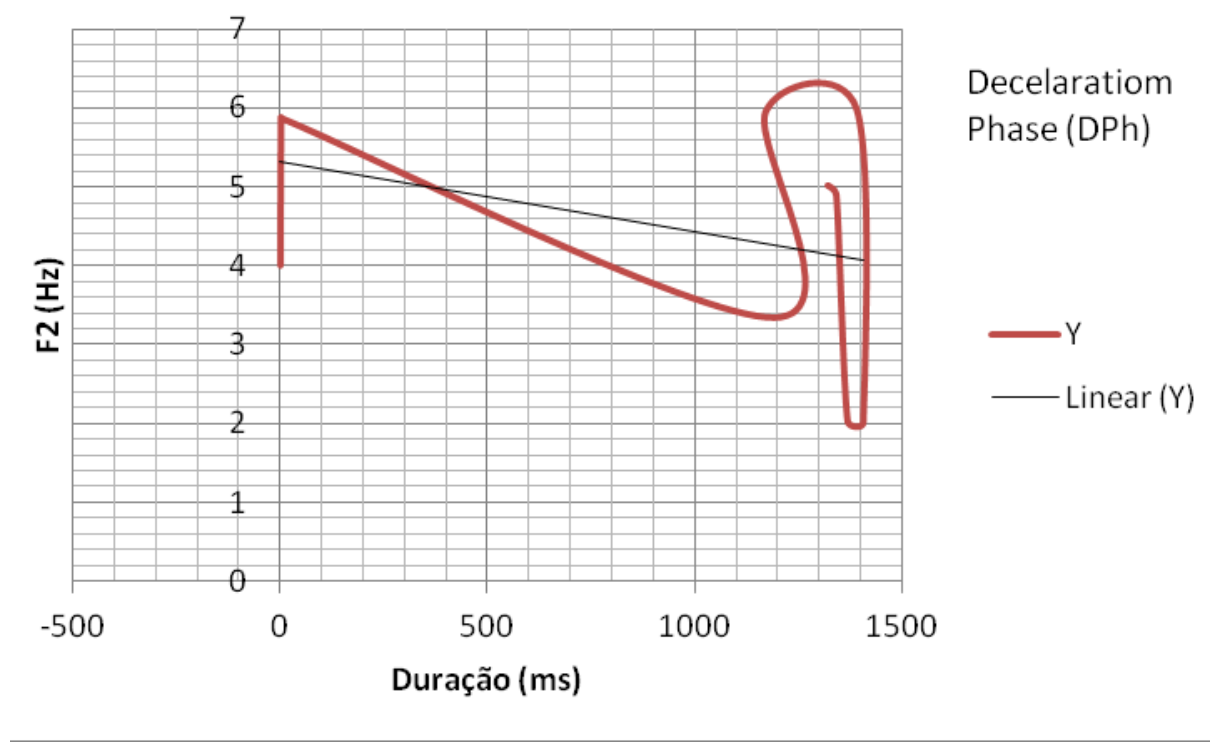

Grafico 1: Fase de desaceleração dos articuladores orais.

No Gráfico 1, observamos uma função linear decrescente da $\mathrm{F} 2(\mathrm{KHz})^{7}$ - eixo $\mathrm{Y}$ em função da duração (ms) - eixo X. Neste sentido, este intervalo não se caracterizou como parte do p-center ou GIPC de acordo com o modelo de Fichs, Perrier e Mooshammer (op. cit). Este modelo desconsidera a fase de desaceleração como parte do ponto de ancoragem perceptual.

Nas Fig. 3 e 4, atestamos que as produções de P[pł] (alg) estão foneticamente equilibradas quanto à duração. Essas figuras também mostram similaridade duracional significativa dos demais GIPCs do enunciado quando comparados entre si.

$\mathrm{O}$ que chama a atenção na Fig. 2 é que o informante, mesmo sendo de nível advanced, desloca o acento métrico para o P-center da segunda janela fonológica, em outras palavras, ao invés de produzir " $\underline{\boldsymbol{A} \boldsymbol{L} \boldsymbol{G}}$ orithm", ele produz "algo $\underline{\boldsymbol{R} \boldsymbol{I}}$ thm". O alinhamento do acento fonológico realizado por este informante é tal qual se faz no português brasileiro

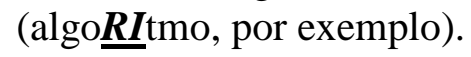

\footnotetext{
${ }^{7}$ No gráfico observamos que o título do eixo Y é "F2 (Hz)". Não utilizamos "KHz" (medidas multiplicadas por 1000 que constam neste trabalho) para denominar o eixo por questões de convenções estabelecidas em estudos de fonética experimental (cf. LADEFOGED; DISNER 2013 e LADEFOGED; JOHNSON, 2011).
} 
Com base nos dados das figuras acima, na tabela 1, temos, respectivamente, a duração em milissegundos (D em $m s$ ) do P-center - P[pł] (alg), onde se localiza o acento frasal (AF), da seguinte forma:

Tabela 1: duração (em $m s)$ do acento frasal da $\varphi$ em análise.

\begin{tabular}{|l|c|}
\hline Fig. $\mathbf{I}-\boldsymbol{P}(\boldsymbol{A F})=\mathbf{2 7 9} \mathbf{m s}$ & Inform. 1 - norte-americano (ingles/L1) \\
\hline Fig. $2-\mathrm{P}(\mathrm{AF})=217 \mathrm{~ms}$ & Inform. $2-$ brasileiro (ingles/L2) \\
\hline Fig. $3-\mathrm{P}(\mathrm{AF})=256 \mathrm{~ms}$ & Inform. 3 - brasileiro (ingles/L2) \\
\hline Fig. $4-\mathrm{P}(\mathrm{AF})=231 \mathrm{~ms}$ & Inform. 4 - brasileiro (ingles/L2) \\
\hline
\end{tabular}

Fonte: Elaborado pelo próprio autor

É possível observar que os aprendizes, durante a aquisição e/ou aprendizado dos processos orais, adquirem a L2 com marcas de TF significativas - ou seja - os falantes transferem o traço [+ silábico] do PB quando produzem o inglês - que é uma língua [+ acentual].

Embora os sujeitos de nossa pesquisa falem dialetos distintos em sua L1 - recifense, pessoense e guarabirense - tal fato não influenciou a produção do ritmo como apontam as Fig. 2, 3 e 4. A variação dialetal da L1 dos sujeitos, neste sentido, influenciaria aspectos segmentais com ambientes fonológicos propensos a tais mudanças como aponta Lado (1957).

Veremos a seguir no Gráfico 2 e Tab. 2 respectivamente, o comportamento silábico mostrando como ocorreu a alternância rítmica (transcrito por IPA) realizado pelos 04 informantes e as medidas duracionais das sílabas envolvidas no evento fonológico acima citado.

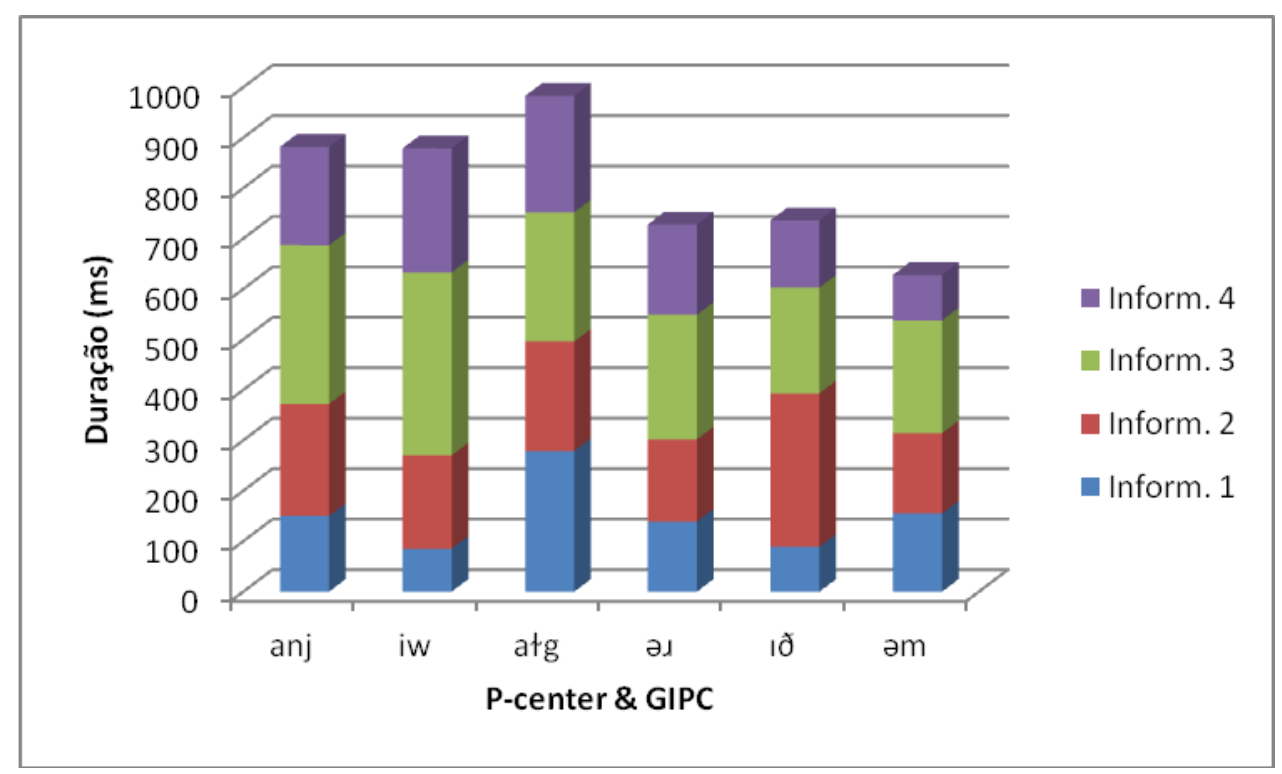

Gráfico 2: Representação em colunas do P-center, GIPC e duração das sílabas que compõem a new algorhythm $(\varphi)$

Tabela 2: Duração em $m s$ das sílabas da frase [a new algorhythm] $\varphi$ 


\begin{tabular}{|lrrrr||}
\hline P \& GIPC & Inform. 1 & Inform. 2 & Inform. 3 & Inform. 4 \\
anj & 150 & 222 & 315 & 195 \\
iw & 85 & 185 & 363 & 246 \\
ałg & 279 & 217 & 256 & 231 \\
əג & 139 & 163 & 247 & 179 \\
Iठ & 89 & 304 & 210 & 133 \\
əm & 155 & 159 & 224 & 90 \\
\hline \multicolumn{5}{l}{}
\end{tabular}

\section{Considerações finais}

Concluímos nesse trabalho e com base nos dados aqui apresentados que a TF de aspectos rítmicos durante a aquisição e/ou aprendizagem do inglês como L2 se dá de forma bastante significativa - mesmo tendo falantes com alto nível de proficiência.

O caráter aplicado de nossa pesquisa é consoante minha prática profissional no período em que atuei como professor de inglês em escolas públicas na tentativa de apontar quais são os melhores caminhos, as melhores estratégias, de se ensinar inglês como L2 de modo a conseguir dos aprendizes uma pronúncia mais inteligível levando em conta processos de TF em produções na pronúncia do aprendiz do inglês como L2; desde aspectos segmentais, silábico-estruturais e, sobretudo, rítmicos e entonacionais, que atingem diretamente a fala espontânea.

Como aponta Alves e Barreto (2012), o professor de língua inglesa deve privilegiar o ensino-aprendizagem priorizando em suas aulas aspectos fonético-fonológicos da L2 para que o processo de aquisição seja mais efetivo. Os autores ainda afirmam que: "a percepçãoprodução dos sons da língua-alvo exerce um fator primordial” (ALVES; BARRETO, 2012, p. 293).

Silva Jr e Silva (2014) corroboram a afirmação de Alves e Barreto (op. cit.) quando apontam que o caminho que tem demonstrado maior eficácia no processo aquisição do inglês é a utilização de listening skills para uma produção bem sucedida.

Aqui provamos que, sob o ponto de vista fonético-acústico, que os brasileiros aqui analisados tenderam a resolver questões do cerne rítmico nas produções em inglês majoritariamente, de acordo com modelos de resolução aplicados a línguas de tipo rítmico [+ silábico] opondo-se ao ritmo acentual que caracteriza o inglês.

Esta hipótese corrobora Silva Jr (2013) quando o autor afirma que manter a regularidade rítmica de um elemento acentual a outro e, ao mesmo tempo, reduzir as sílabas do grupo inter-acentual pode se tornar uma tarefa difícil para falantes brasileiros de inglês como L2. Em línguas como o PB, a isocronia funciona pelo número pronunciado de sílabas em um dado enunciado e não pelo número de elementos acentuais. Desta forma, o falante que tem sua L1 com características silábicas - caso do PB - demonstra uma forte tendência de realizar todas as sílabas e palavras do enunciado de forma igualitária em termos duracionais.

\section{Referências}

ALVES, U.; BARRETO, F. O processamento e a produção dos aspectos fonético-fonológicos da L2. In: LAMPRECHT, R. (Org.). Consciência dos sons da língua: Subsídios teóricos e 
práticos para alfabetizadores, fonoaudiólogos e professores de língua inglesa. 2 ed, Porto Alegre, EDPUCRS, 2012.

AVERY, P.; EHRLICH, S. Common Pronunciation Problems. In: AVERY, P.; EHRLICH, Susan. Teaching American English Pronunciation. New York, Oxford University Press, 2012, pp 96-109.

BARBOSA, P. Syllable-Timing in Brazilian Portuguese: Uma Crítica a Roy Major (Temposilábico em Português do Brasil: a critic to Roy Major). São Paulo, DELTA, v. 16, n. 2, 2000.

BISOL, L. Introdução a estudos de fonologia do português brasileiro, 5 ed. Porto Alegre, EDIPUCRS, 2010.

BOERSMA, P.; WEENINK, D. Praat: doing phonetics by computer (Version 5.4.00). Retrieved from http://www.praat.org, 2014.

CELCE-MURCIA, M. Teaching Pronunciation: A course book and reference guide, 2 ed. New York, Cambridge University Press, 2010.

CLAREY, E.; DIXON, R. Pronunciation Exercises in English (revised ed.). New York, Regents Publication Company, 1963.

COUPER-KUHLEN, E. English Speech Rhythm: form and function in everyday verbal interaction, Philadelphia, John Benjamins Publishing Co., 1993.

DUPOUX, E.; PEPERKAMP, S. Fossil markers of language development: phonological 'deafnesses' in adult speech processing, Oxford, Oxford University Press, 1999.

FICHS, S.; PERRIER, P.; MOOSHAMMER, C. The role of the palate in tongue kinematics: an experimental assessment in VC sequences from EPG and EMMA data. In: Proceedings of 7th European Conference on Speech Communication and Technology. Aalborg, 2001, pp. 1487-1490.

HAYES, B. The phonology of rhythm in English. Linguistic Inquiry 15(1):33-74, 1984.

JENKINS, J. The phonology of English as an International Language. Oxford, Oxford University Press, 2000.

LADO, R. Linguistics across cultures. Ann Arbor: University of Michigan Press, 1957.

NESPOR, M. On the separation of prosodic and rhythmic phonology. In: NESPOR, M.; VOGEL, I. Prosodic Phonology: With a new forward, Berlin, Deutsche Nationalbibliotek, 2007.

PIKE, K. The Intonation of American English, Ann Arbor, University of Michigan Publications, 1945. 
PURPURA, J. Oxford Online Placement Test (OOPT). In: https://www.oxfordenglishtesting.com/. Acessado em 2015.

SCARPA, E. O recurso a níveis superiores na aquisição e na afasia. PaLavra, v. 6, PUCRIO, Editora Trarepa, 2000, pp. 48-62.

SELKIRK, E. Phonology and Syntax: The relation between sound and structure. Cambridge Mass: MIT Press, 1984.

SILVA Jr, L. Interferências Rítmicas do Português Brasileiro no Inglês como L2: O choque acentual. Tese (Doutorado), João Pessoa, 2013.

SILVA Jr, L.; SCARPA, E. Stress clash marks from Brazilian speakers of English as a Foreign Language. In: PROCEEDINGS of EPIP4 4th International Conference on English Pronunciation: Issues \& Practices. Prague, May 21-23, 2015, pp 128-131. Disponível em: http://fu.ff.cuni.cz/epip4/docs/EPIP4-Proceedings.pdf.

SILVA Jr, L.; SILVA, R. O Ensino de pronúncia na formação do aluno de Letras: contribuições da habilidade "Listening". In: Anais ENID/UEPB (2014) - v. 1, n. 2, 2014. Disponível em: http://www.editorarealize.com.br/revistas/eniduepb/anais.php.

SILVEIRA, A. P. Deslocamento de acento na aquisição da língua inglesa como segunda língua. Letras de Hoje, v. 46, n. 2, p. 104-112. Porto Alegre, 2011.

STAMPE, D. A dissertation on natural phonology. Tese (Doutorado). Chicago University, 1973.

Recebido em: dezembro de 2015.

Aprovado em: março 2016. 